\title{
Laparoscopic transcystic common bile duct exploration in patients with a nondilated common bile duct
}

\author{
Lu Fang ${ }^{1 \#}$, Jian Huang ${ }^{1 \#}$, Hao Zheng ${ }^{2 \#}$, Zhi-Qing Duan ${ }^{1}$, Tian-De Liu ${ }^{1}$, Hu Xiong ${ }^{1}$, Wen Li ${ }^{1}$, \\ Xiao-Wei Fu ${ }^{1}$, Jian-Feng Gao ${ }^{1}$, Hao Le ${ }^{1}$, Wei Hu ${ }^{1}$, Bo Liang ${ }^{1}$, Xin-Gen $\mathrm{Zhu}^{2,3,4}$ \\ ${ }^{1}$ Department of General Surgery, The Second Affiliated Hospital of Nanchang University, Nanchang, China; ${ }^{2}$ Third Department of Hepatic Surgery, \\ Eastern Hepatobiliary Surgery Hospital, Second Military Medical University, Shanghai, China; ${ }^{3}$ Department of Neurosurgery, The Second Affiliated \\ Hospital of Nanchang University, Nanchang, China; ${ }^{4}$ Institute of Neuroscience, Nanchang University, Nanchang, China \\ Contributions: (I) Conception and design: L Fang, B Liang, XG Zhu; (II) Administrative support: L Fang, B Liang, XG Zhu; (III) Provision of study \\ materials or patients: J Huang, H Zheng, TD Liu, H Xiong, W Li, XW Fu; (IV) Collection and assembly of data: J Huang, H Zheng, ZQ Duan, \\ J Gao, H Le, W Hu; (V) Data analysis and interpretation: L Fang, J Huang, H Zheng, ZQ Duan (VI) Manuscript writing: All authors; (VII) Final \\ approval of manuscript: All authors. \\ \#These authors contributed equally to this work. \\ Correspondence to: Bo Liang. Department of General Surgery, The Second Affiliated Hospital of Nanchang University, Nanchang, China. \\ Email: 1b2087@163.com; Xin-Gen Zhu. Department of Neurosurgery, The Second Affiliated Hospital of Nanchang University, Nanchang, China. \\ Email: ndefy89006@ncu.edu.cn.
}

Backgroundz Laparoscopic transcystic common bile duct exploration (LTCBDE) is the minimally traumatic surgical method for the treatment of choledocholithiasis secondary to cholecystolithiasis with dilated common bile duct (CBD). However, no report exists concerning LTCBDE in patients with nondilated CBD. The purpose of this study was thus to explore the safety, efficacy, and feasibility of LTCBDE in patients with choledocholithiasis secondary to cholecystolithiasis with nondilatation of the CBD.

Methods: We retrospectively analyzed 47 patients with choledocholithiasis secondary to cholecystolithiasis who were treated with LTCBDE at the Second Affiliated Hospital of Nanchang University from January 2017 to August 2021 (all the patients had undergone endoscopic retrograde cholangio-pancreatography treatment, but this failed due to various reasons). Clinical data on disease characteristics, methods for cystic duct incision and CBD stone extraction, and surgical outcomes were collected and reviewed. Each patient was followed up for more than 3 months.

Results: There were 47 patients in this study, including 21 females and 26 males, with their ages ranging from 15 to 82 years $(51 \pm 15$ years). All patients were treated with surgery, and the CBD stones were removed successfully. Among these patients, 45 underwent LTCBDE for the removal of stones in the CBD, with failure occurring in 2 patients who then accepted laparoscopic common bile duct stone removal (LCBDE) $+\mathrm{T}$ tube drainage. The diameter of the cystic duct was $0.30-0.73 \mathrm{~cm}(0.60 \pm 0.07 \mathrm{~cm})$, the diameter of the CBD was $0.60-0.80 \mathrm{~cm}(0.73 \pm 0.05 \mathrm{~cm})$, the operation time was $75-220$ minutes $(159 \pm 33$ minutes $)$, and the postoperative hospital stay was $2-13$ days (6 \pm 2 days). None of the patients experience any serious postoperative complications, and all were discharged safely. During the follow-up, no postoperative biliary stenosis, bile leakage, or other complications occurred.

Conclusions: LTCBDE is feasible to treat patients with choledocholithiasis secondary to cholecystolithiasis with nondilatation of the CBD. This choice of treatment plan reduces the length of hospital stay and the occurrence of postoperative complications. However, it is recommended that this be attempted on the basis of the experience of LTCBDE with dilated CBD.

Keywords: Laparoscopic transcystic common bile duct exploration (LTCBDE); transcystic; cystic duct incision; common bile duct (CBD) 
Submitted Nov 25, 2021. Accepted for publication Dec 17, 2021.

doi: 10.21037/apm-21-3609

View this article at: https://dx.doi.org/10.21037/apm-21-3609

\section{Introduction}

Choledocholithiasis secondary to cholecystolithiasis is a common clinical disease, and its incidence in patients with cholecystolithiasis is about $10-15 \%(1,2)$. It can lead to serious complications, such as acute obstructive suppurative cholangitis (AOSC), biliary septic shock, and acute biliary pancreatitis (ABP), among others. These diseases seriously threaten the health of patients and can even be life-threatening (3). There are many treatments for this disease, including choledocholithotomy + cholecystectomy, laparoscopic choledocholithotomy (LCBDE) $+\mathrm{T}$ tube drainage + laparoscopic cholecystectomy (LC), LCBDE + stage I suture + LC, endoscopic retrograde cholangiopancreatography $(\mathrm{ERCP})+\mathrm{LC}$, and laparoscopic cholecystectomy through the common bile duct (LTCBDE) + LC (4-8).

With the advancement of technology, the practice of open choledocholithotomy + cholecystectomy has gradually decreased, and the number of LCBDE procedure has gradually risen $(9,10)$. After LCBDE, a T tube or stage I suture can be placed according to the situation. Placing a $T$ tube after LCBDE is a safe method and can prevent many postoperative complications and the occurrence of postoperative bile leakage, while being conducive to the treatment of postoperative residual stones and the recovery of liver function after surgery (11). However, its shortcomings are also obvious. These include the inconvenience of the for the patient of carrying the $T$ tube for an extended period and the impact of the loss of $\mathrm{Na}+$ on the patient's internal environment (11-13). ERCP + LC is a step-by-step method that was developed to treat Choledocholithiasis secondary to cholecystolithiasis. In this procedure, ERCP is first performed to the remove stones in the common bile duct (CBD), after which LC is applied. ERCP is a less traumatic method of stone removal, but it requires incising the duodenal papillary sphincter, which makes it possible for some patients to develop reflux cholangitis, with a small portion of patients needing to undergo bile duct-jejunum Roux-en-Y anastomosis to solve this problem (14). LTCBDE + LC is the most physiologically ideal surgical procedure. It inserts the choledochoscope through the cystic duct to remove the stones in the CBD, and then simultaneously ligates the stump of the cystic duct and removes the gallbladder. This not only avoids the major trauma of CBD incision, but also avoids the necessity of long-term $\mathrm{T}$ tube use postoperation and protects the integrity of duodenal papillary sphincter function (8). However, operations using this technology are relatively difficult, which restricts this methods popularization and application. The most challenging aspect of this technique is inserting the choledochoscope into the CBD through the cystic duct. Previous articles published by our team proposed 3 ways to insert the choledochoscope into the CBD through the cystic duct $(15,16)$. For patients with dilated cystic duct, we directly incise the cystic duct transversely, and thus the choledochoscope can easily enter the CBD. For patients with thinner cystic duct, we complete a T-shaped incision of the cystic duct or a microincision at the cystic ductCBD confluence to solve this technical problem (16). In applying the abovementioned methods, we can successfully perform LTBCDE in most patients. If we fail to enter the CBD through the cystic duct after repeated attempts during the operation, we can change the operation strategy and use LCBDE + LC. Currently, this technology has been reported and applied in multiple medical centers, benefiting many patients $(8,15,17-19)$.

However, we frequently encounter patients whose CBD is not dilated during the operation, and undoubtedly, ERCP + LC should be the first choice for these patients (20). However, due to some patients having previously undergone Billroth-II or Roux-en-Y gastric surgery, the presence of duodenal papillary diverticulum, patient intolerance, or operator or technical difficulties, among other issues, ERCP may fail, thus making the treatment of these patients extremely problematic. If we incise CBD in this situation, it may cause the stenosis of the CBD after the operation, or result in a major quality of life reduction due to the long-term use of a T tube to support the CBD (21-23). Consequently, we speculated whether the application of LTCBDE + LC could solve this issue.

We thus conducted a retrospective study of LTCBDE + LC in patients with nondilated CBD, aiming to explore its safety, efficacy, and feasibility. We conducted this study on 
the basis of the relative maturity of LTCBDE and patients with ERCP failure.

We present the following article in accordance with the STROBE reporting checklist (available at https://dx.doi. org/10.21037/apm-21-3609).

\section{Methods}

\section{Patients}

From January 2017 to August 2021, 47 patients underwent LTCBDE + LC at the Second Affiliated Hospital of Nanchang University. All were considered for ERCP before surgery, but failed for the following reason: previously Billroth-II or Roux-en-Y gastric surgery, presence of duodenal papillary diverticulum, patient intolerance, operator technical issues, or other reasons. Preoperative diagnosis was based on clinical features, laboratory examinations, and imaging examination results. These included the patient experiencing right upper abdomen pain and jaundice, with laboratory examinations indicating abnormal liver function, and magnetic resonance imaging $(\mathrm{MRI})+$ magnetic resonance cholangiopancreatography (MRCP) indicating CBD stones and gallbladder stones. In this group of patients, the diameter of the cystic duct was $\geq 0.30 \mathrm{~cm}$, and the diameter of the CBD was $0.6-0.80 \mathrm{~cm}$ (Table 1). This study excluded patients with intrahepatic bile duct stones or Mirizzi syndrome, and those suspected for cholangiocarcinoma.

\section{Clinical data}

The clinical data examined in this study included the patient's demographic characteristics [i.e., age, sex, American Society of Anesthesiologists (ASA) class, laboratory tests, imaging data, and reasons for ERCP failure], patient disease characteristics (i.e., diameter of cystic duct and CBD) (Table 1), and the results of the operation (i.e., cystic duct incision, stone removal method, management of the cystic duct stump, operation duration, and postoperative adverse events; Table 2). MRCP was used to evaluate the anatomy of the bile duct and the number of stones before operation. All procedures performed in this study involving human participants were in accordance with the Declaration of Helsinki (as revised in 2013). The study was approved by the Ethics Committee of the Second Affiliated Hospital of Nanchang University (No. 2016126) and informed consent was taken from all the patients.

\section{LTCBDE operative techniques}

The LTCBDE operative techniques relevant to this study are described below. The patient was placed in a supine position with head and left side tilted $15^{\circ}$. After general anesthesia, $\mathrm{CO}_{2}$ pneumoperitoneum was established. We used the 4-hole method for the operation: the laparoscopic observation hole was located below the umbilicus, and a $30^{\circ}$ angle laparoscope was inserted; a $12-\mathrm{mm}$ trocar was placed under the xiphoid process as the main operation hole, and a $5-\mathrm{mm}$ trocar was placed $5 \mathrm{~cm}$ below the midclavicular line on the right side; another $5-\mathrm{mm}$ trocar was placed $8 \mathrm{~cm}$ below the anterior axillary line and the costal margin as an auxiliary operation hole, and the pressure of the pneumoperitoneum was maintained at 12-14 $\mathrm{mmHg}$ (Figure 1).

We have previously described the LTCBDE operative steps (16). The adipose tissue in the Calot triangle is carefully dissected and removed, and the cystic artery is clipped and cut off using absorbable clips. The proximal end of the cystic duct is clamped to prevent the stones and bile from flowing out of the gallbladder. The ductCBD confluence of the cystic is clearly exposed, and there is no fatty tissue. We select different cystic duct incision methods according to the diameter of the cystic duct and the size of the stones in the CBD. Generally, we first incise the anterior wall of the cystic duct transversely and directly attempt to enter the choledochoscope into the CBD when the diameter of the cystic duct is $\geq 5 \mathrm{~mm}$ (Figure $2 A$ ). If the diameter of the cystic duct is $<5 \mathrm{~mm}$, we insert a support tube into the cystic duct under the guidance of the support tube. A T-shaped incision is then made on the anterior wall of the cystic duct, and the choledochoscope is inserted (Figure 2B). If the choledochoscope still cannot enter the $\mathrm{CBD}$, the cystic duct-CBD confluence is incised slightly and then the choledochoscope is inserted (Figure 2C).

The $5-\mathrm{mm}$ choledochoscope enters the CBD from the trocar under the xiphoid process through the cystic duct, and the CBD stones are directly exposed. CBD stones are usually removed through the cystic duct using a wire basket (Figure $3 A$ ). If the CBD stones cannot be removed by the above method, laser lithotripsy is used (Figure $3 B$ ). After removing the stones, we need to check the CBD and intrahepatic bile ducts $2-3$ times to ensure that all of the stones have been removed. The number of stones removed in the CBD should be consistent with the number reported by MRCP or Color Doppler ultrasound to avoid residual stones. After the stones in the CBD are completely removed, the cystic duct is ligated with absorbable clips 


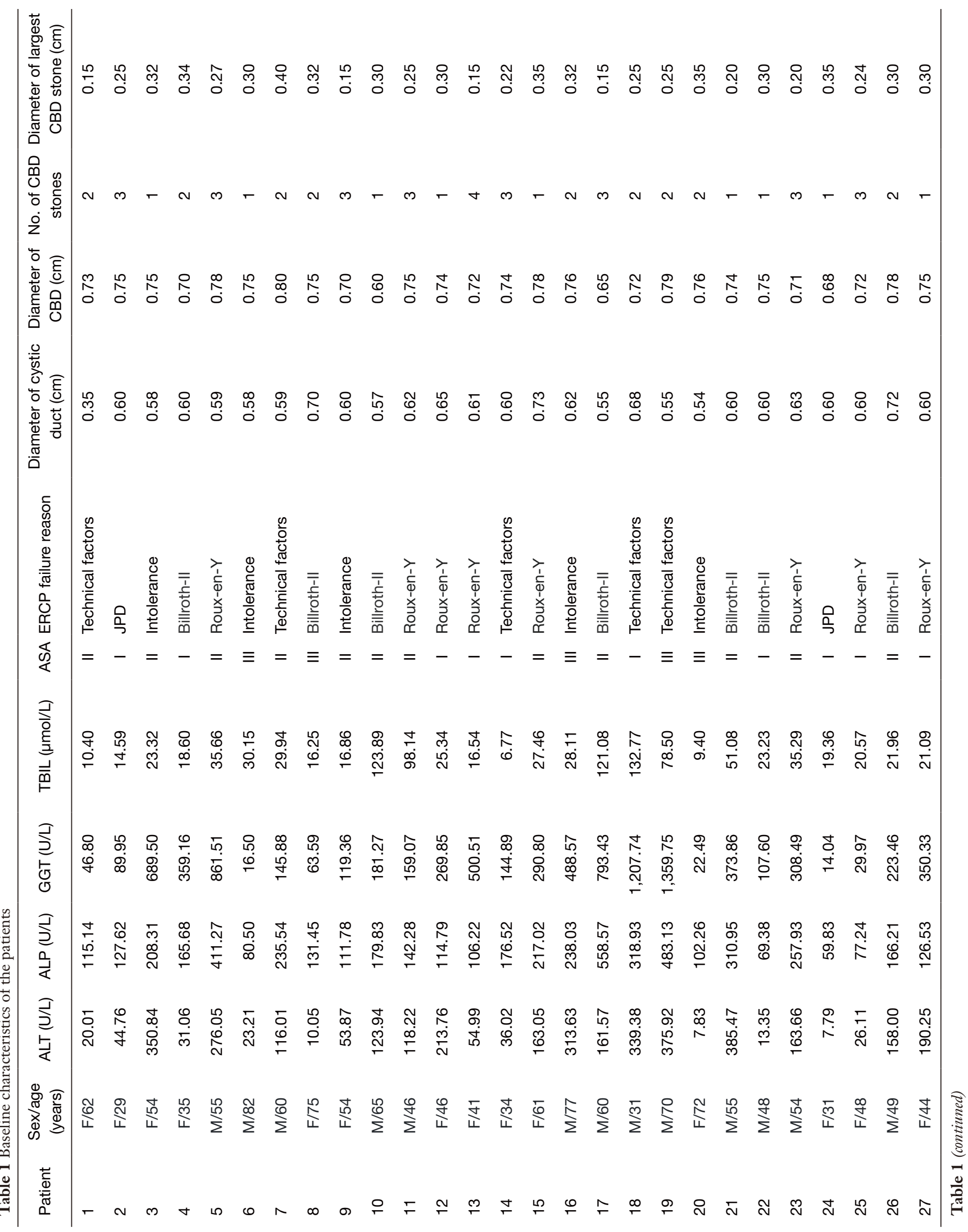




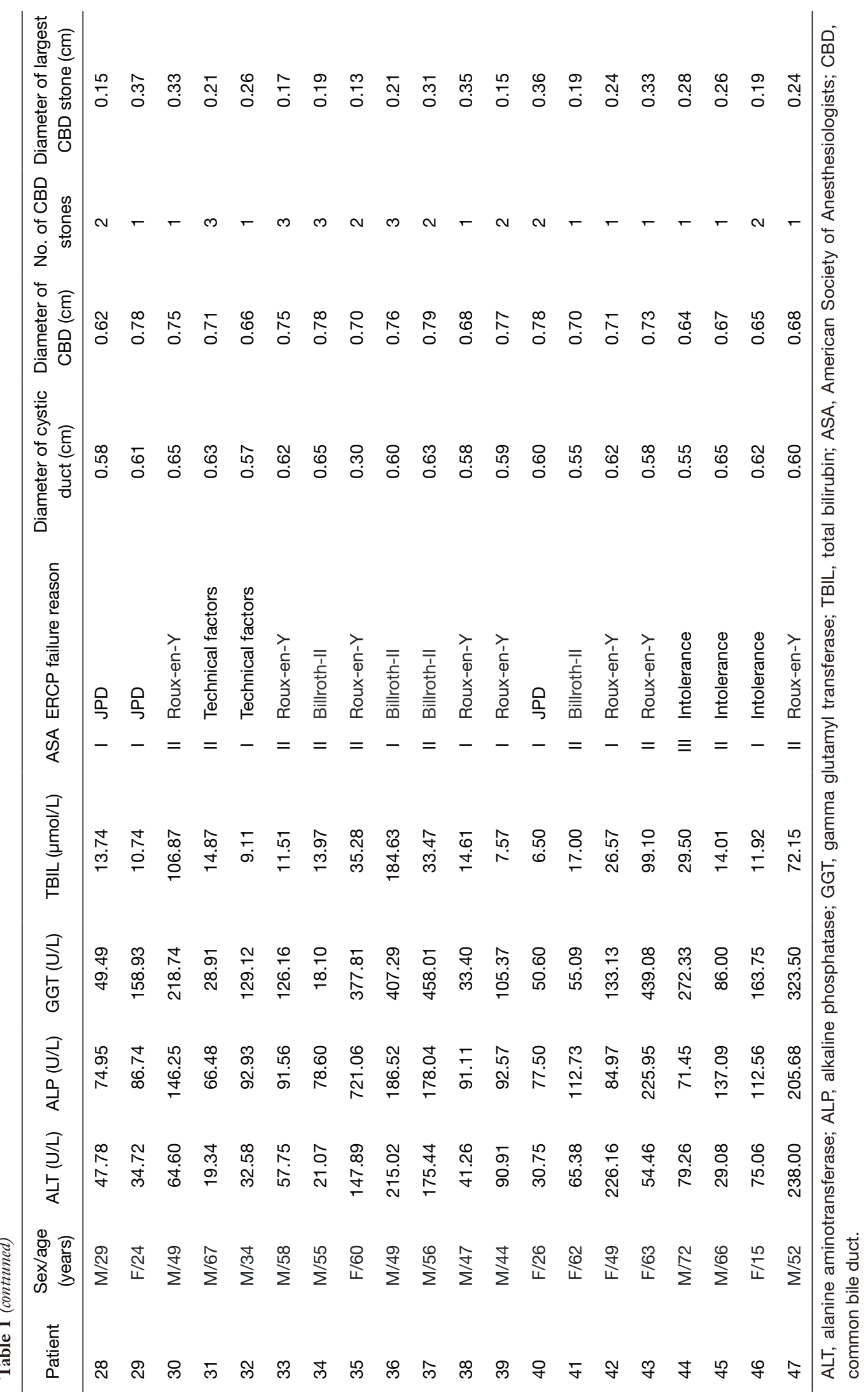


Table 2 Operative outcome

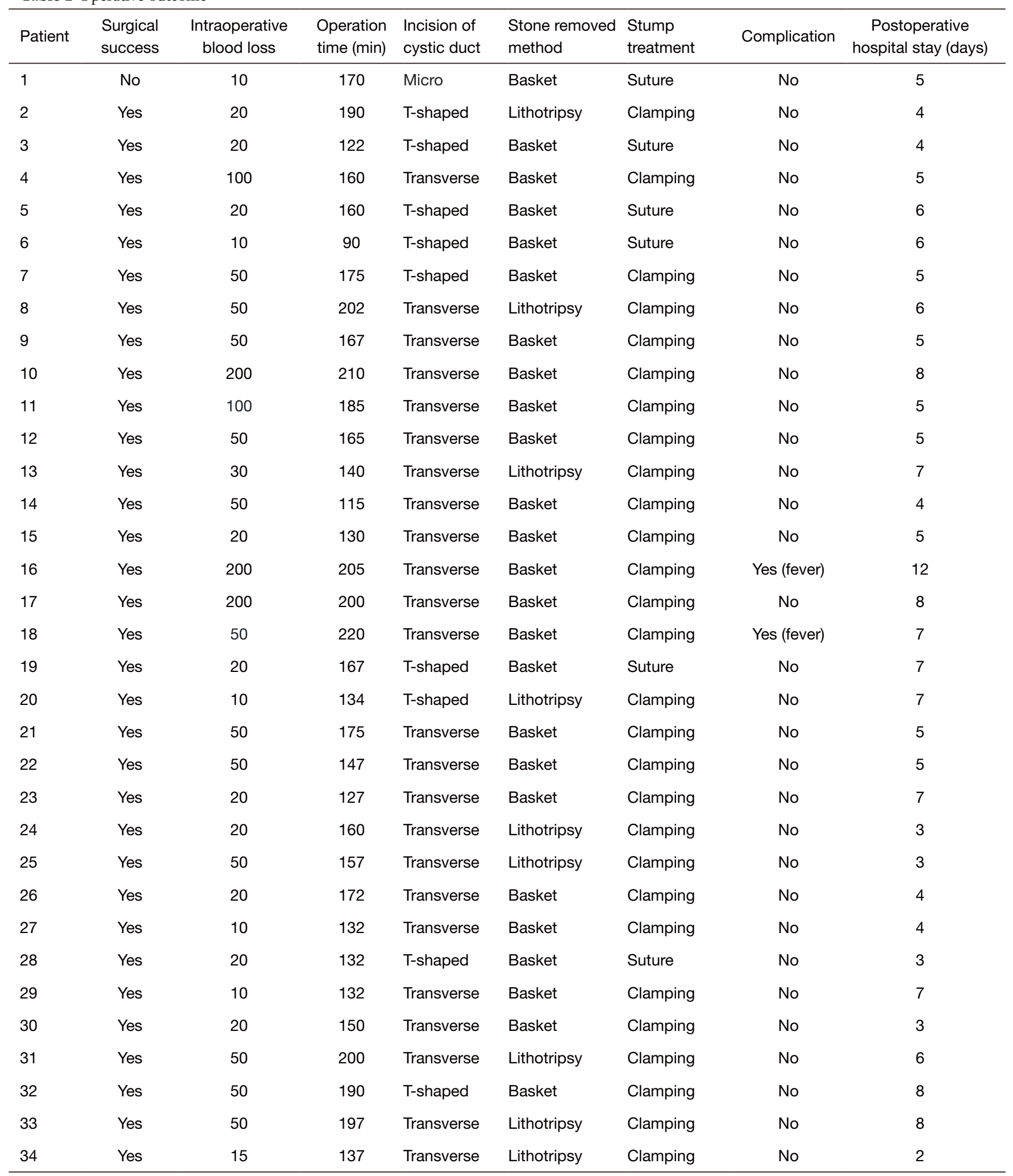

Table 2 (contiuned) 
Table 2 (contiuned)

\begin{tabular}{|c|c|c|c|c|c|c|c|c|}
\hline Patient & $\begin{array}{l}\text { Surgical } \\
\text { success }\end{array}$ & $\begin{array}{l}\text { Intraoperative } \\
\text { blood loss }\end{array}$ & $\begin{array}{l}\text { Operation } \\
\text { time (min) }\end{array}$ & $\begin{array}{l}\text { Incision of } \\
\text { cystic duct }\end{array}$ & $\begin{array}{l}\text { Stone removed } \\
\text { method }\end{array}$ & $\begin{array}{l}\text { Stump } \\
\text { treatment }\end{array}$ & Complication & $\begin{array}{c}\text { Postoperative } \\
\text { hospital stay (days) }\end{array}$ \\
\hline 35 & Yes & 10 & 125 & Micro & Basket & Suture & No & 4 \\
\hline 37 & Yes & 20 & 192 & Transverse & Basket & Clamping & No & 7 \\
\hline 40 & Yes & 10 & 132 & Transverse & Lithotripsy & Clamping & No & 4 \\
\hline 41 & Yes & 30 & 106 & T-shaped & Basket & Suture & No & 3 \\
\hline 42 & Yes & 10 & 201 & Transverse & Basket & Clamping & No & 7 \\
\hline 46 & Yes & 15 & 140 & Transverse & Basket & Clamping & No & 5 \\
\hline 47 & Yes & 5 & 122 & Transverse & Basket & Clamping & No & 6 \\
\hline
\end{tabular}

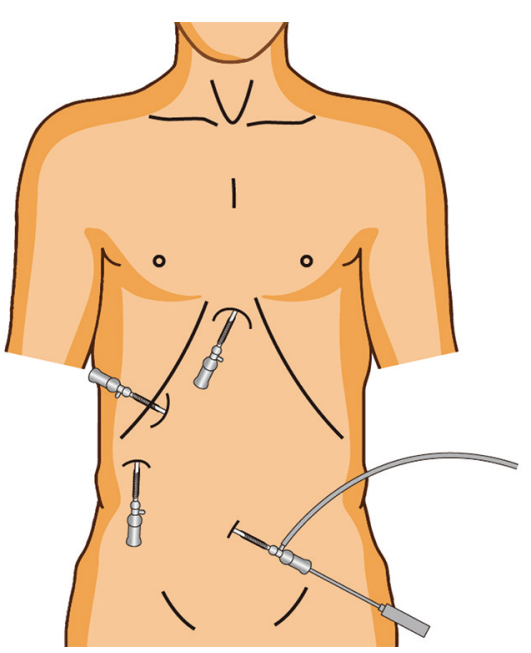

Figure 1 The patient's surgical position and trocar layout.

(Figure 3C) or sutures (Figure 3D). The cystic duct-CBD confluence is relatively enlarged, and thus only the anteriorlateral wall of the CBD and the lateral-posterior wall of the cystic duct are sutured, so the risk of postoperative bile duct stenosis can be avoided. Finally, the gallbladder and stones are removed, and drainage tube is placed at the Winslow hole. For patients who cannot undergo LTCBDE, we must perform LCBDE + T tube drainage.

\section{Postoperative care and follow-up}

We performed a statistical analysis on the data related to postoperative routine blood, liver function, bile leakage, drainage tube removal time, hospital stay, etc. Patients were followed up in outpatient clinics in the first 2 weeks after discharge, after which the patients were followed up by telephone every 3 months. If the patients had bilirubin abnormalities, further MRCP examinations were required to screen the possibility of bile duct stenosis after surgery. Other follow-up indicators included the patient's general condition, diet, and discomfort associated with surgery, among others.

\section{Statistical analysis}

SPSS20.0 software was used. The measurement data with normal distribution were expressed by mean \pm standard deviation, and the categorical data were expressed by the number of cases.

\section{Results}

\section{General situation}

A total of 21 females and 26 males were included in this study, with an average age of 51.4 years. Among them, 8 cases failed ERCP due to intolerance, 7 cases failed 
A

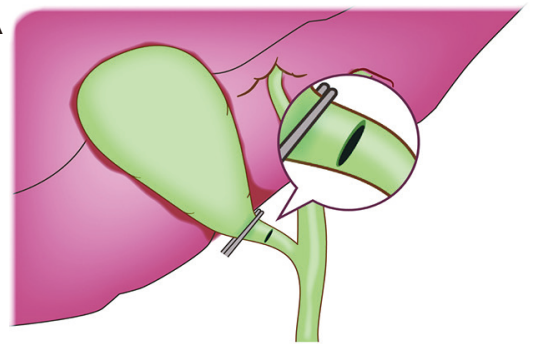

A transverse incision of cystic duct

C

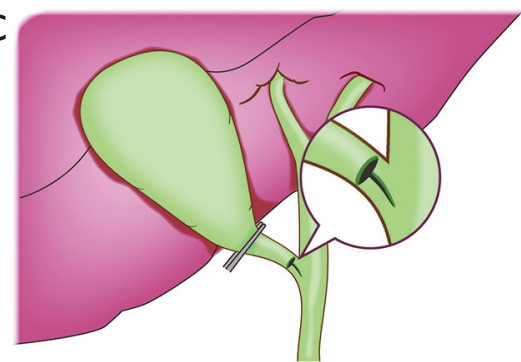

B

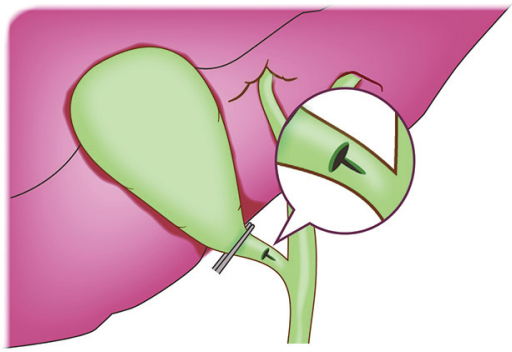

A T-shaped incision of cystic duct

A micro-incision of cystic duct

Figure 2 The different methods for incising the cystic duct. (A) Transverse incision of the anterior wall of the cystic duct. (B) T-shaped incision of the anterior wall of the cystic duct. (C) Microincision of the cystic duct-CBD confluence. CBD, common bile duct.

A

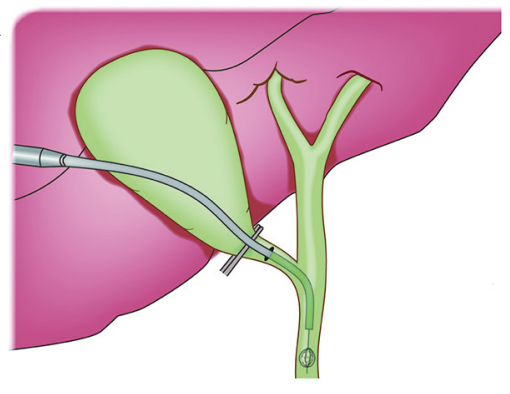

Basket

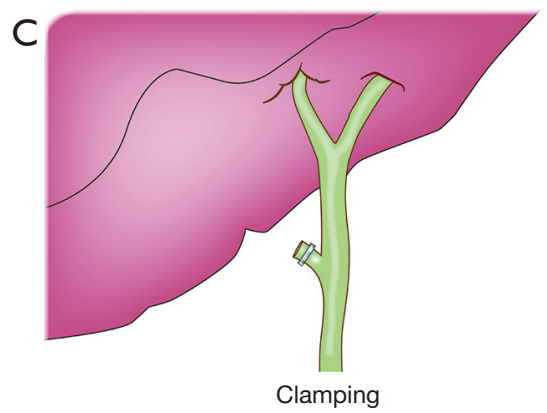

B

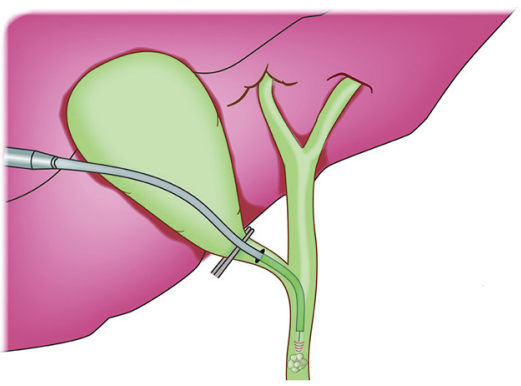

Lithotripsy

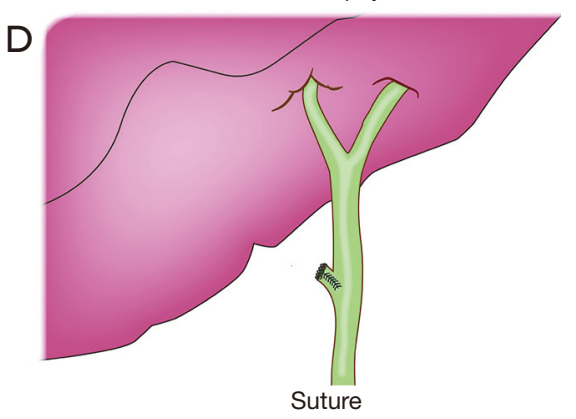

Figure 3 Stones are removed from the CBD through the cystic duct, and the cystic duct stump is managed. (A) CBD stones are removed through the cystic duct using a wire basket. (B) If the CBD stones cannot be removed by wire basket, laser lithotripsy is used. (C) The cystic duct is ligated with absorbable clips. (D) The cystic duct-CBD confluence is sutured by absorbable sutures. CBD, common bile duct. 


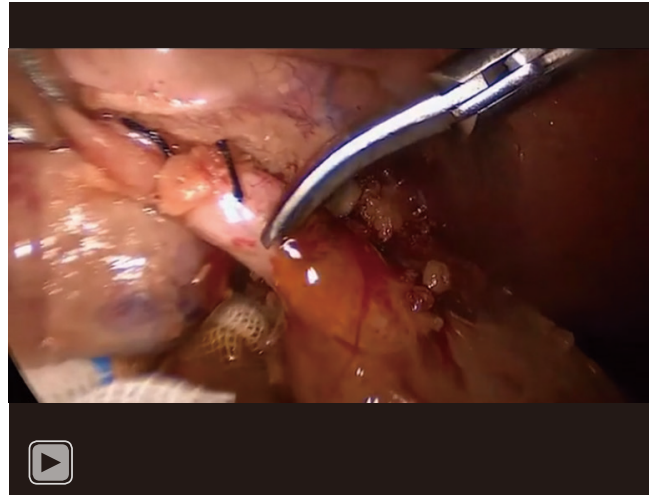

Video 1 A transverse incision of cystic duct.

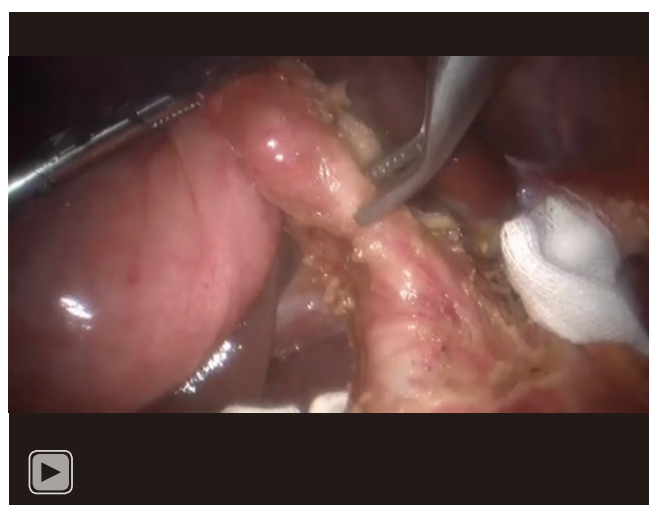

Video 2 A T-shaped incision of cystic duct.

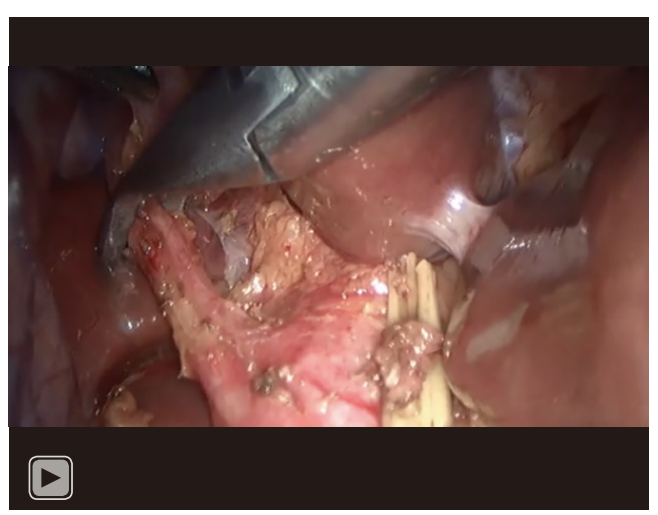

Video 3 A microincision of the cystic duct-dilated common bile duct (CBD) confluence.

ERCP due to technical reasons, 17 cases had a history of Billroth-II or Roux-en-Y gastric surgery, and 5 cases had preoperative imaging examinations indicating duodenal papillary diverticulum and did not undergo ERCP (Table 1).
All patients underwent liver function tests within 3 days before operation which revealed the following results: alanine aminotransferase (ALT) 7.79-385.47 (average 117.56) U/L, gamma glutamyl transferase (GGT) 14.04-1,359.75 (average 273.47) U/L, alkaline phosphatase (ALP) 59.83-721.06 (average 175.06) U/L, and total bilirubin (TBIL) 6.50-184.63 (average 38.07) $\mu \mathrm{mol} / \mathrm{L}$. The diameter of the cystic duct ranged from 0.30 to $0.73(0.60 \pm 0.07) \mathrm{cm}$, and the diameter of the CBD ranged from 0.60 to $0.80(0.73 \pm 0.05) \mathrm{cm}$ (Table 1$)$.

\section{Intraoperative conditions}

All patients were operated on with the 4-hole method (Figure 1). The CBD stones of 47 patients were removed successfully, 45 of whom underwent LTCBDE; in 2 patients' insertion of the 5 -mm choledochoscope through the cystic duct was not possible, and the plan was changed during the operation to perform LCBDE $+\mathrm{T}$ tube drainage (Table 2). There was no conversion to laparotomy. For cystic duct incision in 45 LTCBDE patients, 31 cases underwent cystic duct transverse incision and ligation of the cystic duct with absorbable clips (Figure 3C; Video 1), 14 cases underwent cystic duct T-shaped incision (Video 2), and 2 cases underwent incision at the cystic duct-CBD confluence (Table 2; Video 3). For T-shaped incision and microincision, absorbable sutures were needed to suture the cystic duct-CBD confluence (Figure 3D). In these 45 patients, a wire basket was needed to remove the stones in the CBD (Figure 3A; Table 2), and in 2 cases, the stones were embedded in the CBD and could not be taken out directly with the wire basket (Figure 3B; Table 2). The range in operation time was 75-220 $(159 \pm 33)$ minutes. The estimated blood loss during the operation was 5 to $200 \mathrm{~mL}$, and no blood transfusion was required during any operation (Table 2). In all patients, drainage tube placement at the Winslow hole was required.

\section{Postoperative situation}

Postoperative hospital stays ranged from 2 to $13(6 \pm 2)$ days, and 2 patients developed fever after operation but recovered after anti-infection treatment. The drainage tube was removed from 2 to 4 days postoperatively (Table 2), and 2 patients with T-tube drainage returned to the hospital 3 months after the operation and underwent T-tube angiography, but no residual stones were found. The T-tubes were removed the next day after the angiography. The follow-up time ranged from 3 to 12 months, with an 
average of 8.5 months, and there were no complications such as bile duct injury, stenosis, or residual stones.

\section{Discussion}

No standard surgical treatment for patients with choledocholithiasis and gallstones has been developed thus far. As there is no need to destroy the function of the duodenal papillary sphincter and the treatment of the disease can be solved in a minimally invasive condition, $\mathrm{LCBDE}+\mathrm{LC}+\mathrm{T}$ or stage I suture has seen increased acceptance, and may become the first choice for the treatment of the disease in the situation of CBD dilation $(24,25)$. In terms of the optimal timing of surgical treatment in patients presenting concurrent choledocholithiasis, we generally evaluate based on two factors: the first is the time factor. It is best to perform the surgery within 72 hours of the diagnosis. At this time, the degree of abdominal adhesion and inflammation is less, and the surgery is easier to operate. The second factor is liver function. The liver function before the operation should not be severely damaged. If the bilirubin is high before the operation, we need to place a $T$ tube during the operation. In terms of the efficiency of stone removal, we believe that LCBDE is more efficient than ERCP, especially for patients with multiple stones in the CBD. Laparoscopy can remove all stones under direct vision and can also avoid the residual stones. However, after ERCP, we need to do endoscopic nasobiliary drainage (ENBD) to avoid the residual stones and pancreatitis, and cholangiography should be used before the ENBD tube is removed. However, in the case of stage I suture, it is necessary to ensure that the stones in the CBD are completely removed. The main measures required for accomplishing include ensuring that the number of stones removed and the number of stones on the imaging are the same and that water is not used for pressure flushing during the operation, as this could cause the stones to move to the intrahepatic bile duct and become hidden without being discovered. After the operation, patients with abdominal pain, jaundice, fever, or other symptoms must be hospitalized for further investigation into the possibility of residual stones in the CBD and for timely examination and treatment.

For patients with choledocholithiasis secondary to cholecystolithiasis with nondilated CBD, our preferred method is ERCP + LC, which can prevent postoperative CBD stenosis and even CBD damage caused by surgery (20). However, we often face a difficult situation in which ERCP cannot be successfully implemented when encountering this type of patient, and thus other methods need to be implemented in treating the disease. Our initial strategy for the operation of these patients is to perform LCBDE + LC. During the operation, a thin $\mathrm{T}$ tube is placed in the CBD, and long-term support (about 3 months) is required to prevent postoperative CBD stenosis. We found that longterm indwelling of T-tubes is a substantial inconvenience to patients which can seriously affect their quality of life.

Therefore, based on experience from a large number of LTCBDE cases, we tried to perform LTCBDE in patients whose CBD is not dilated and cannot be operated on by ERCP. In theory, if the CBD stones are secondary to gallstones, the cystic duct will be dilated to a certain extent, which provides a theoretical basis for us to incise the cystic duct. When performing this type of surgery, the biggest difficulty is inserting the choledochoscope into the CBD through the cystic duct. We have attempted to overcome this difficulty with transverse incision, T-shaped incision, and cystic duct-CBD microincision. We can also use balloon expansion to expand the cystic duct or insert a support tube into the cystic duct to guide the choledochoscope toward the CBD and incise along the anterior wall of the cystic duct to avoid cutting the anterior and posterior walls of the cystic duct at the same time.

After the choledochoscope enters CBD, we do not recommend using water for pressure flushing, as this can cause some stones to flow back into the intrahepatic bile duct from where they cannot be rediscovered. In patients with incarcerated choledochal stones, the wire basket cannot be directly used, and they must be smashed and taken out with lithotripsy equipment.

Managing the stump of the cystic duct is also an important issue. For patients in whom a transverse incision is performed, we can use absorbable clips directly after stone removal. For the T-shaped incision that does not reach the confluence, absorbable clips can also be used. For a T-shaped incision that has reached the confluence and microincision, we need to suture the anterior-lateral wall of the CBD and the lateral-posterior wall of the cystic duct. In this way, we can avoid CBD stenosis and bile leakage. In terms of the risk of bile leakage after LTCBDE, we think it is mainly avoided from two aspects: First, it is necessary to make sure that the stones in the CBD are taken out, otherwise the residual stones after the operation will cause CBD obstruction again, and bile leakage will occur after the pressure rises. Second, the incision of the CBD and cystic 
duct should be sutured all the way to avoid bile leakage.

Liver function needs to be tested again before patients leave the hospital. The outpatient test is performed 2 weeks after the operation and determines whether the patient has abdominal pain, jaundice, fever, or other symptoms of biliary obstruction. For suspicious patients, we need to perform MRCP again after surgery to check for residual stones in the CBD. The potential causes of the recurrence of choledocholithiasis after surgery may include: first, residual CBD stones during the operation, second, duodenal papillary sphincter relaxation, causing reflux cholangitis and stone formation. If there are residual stones in the $\mathrm{CBD}$, the next treatment may become particularly challenging, but in our experience, this situation has not arisen. Indeed, care must be taken to make a precise evaluation before surgery, and the number of stones removed during the operation should be consistent with those observed by imaging.

To the best of our knowledge, this report presents the first clinical description of LTCBDE in the treatment of cholelithiasis with nondilated CBD, and we verified its safety, efficacy, and feasibility. However, considering that there are certain difficulties with the use of this technology, it is recommended to be applied in conjunction with relatively mature LTCDBE technology. In this report, the clearance rate of bile duct stones in the 47 patients was $100 \%$, and no complications occurred. This group of patients with cholelithiasis benefited from LTCBDE in a single operation, which minimized the risk of bile duct stenosis and obstruction, bile leakage, rupture of the Oddi sphincter, pancreatitis, and perforation. Moreover, this method avoids the ERCP incision of the sphincter and the LCBDE incision of the CBD, thus minimizing the complications associated with ERCP and LCBDE. Our research still has some limitation: First, the number of patient samples in this study is too small, and a large sample study should be added for verification. Second, this study is a retrospective analysis, which is likely to cause some deviations in the results, it needs to be further confirmed by multi-center clinical trials.

\section{Conclusions}

LTCBDE is a safe, effective, and feasible technique in the treatment of choledocholithiasis with no dilatation of the CBD. Considering the technical difficulty of LTCBDE, it is recommended that LTCBDE be performed in patients whose CBD is not dilated and for patients who have failed ERCP, but only under the circumstances that relatively mature LTCBDE technology can be used.

\section{Acknowledgments}

Funding: This research was funded by grants from the National Natural Science Foundation of China (Nos. 82160578 and 32000542); the Natural Science Foundation of Jiangxi Province, China (Nos. 20202BABL206095 and 20202BAB216029); and the Health Department of Jiangxi Province, China (Nos. 20198020, 202130346).

\section{Footnote}

Reporting Checklist: The authors have completed the STROBE reporting checklist. Available at https://dx.doi. org/10.21037/apm-21-3609

Data Sharing Statement: Available at https://dx.doi. org/10.21037/apm-21-3609

Conflicts of Interest: All authors have completed the ICMJE uniform disclosure form (available at https://dx.doi. org/10.21037/apm-21-3609). The authors have no conflicts of interest to declare.

Ethical Statement: The authors are accountable for all aspects of the work in ensuring that questions related to the accuracy or integrity of any part of the work are appropriately investigated and resolved. All procedures performed in this study involving human participants were in accordance with the Declaration of Helsinki (as revised in 2013). The study was approved by the Ethics Committee of the Second Affiliated Hospital of Nanchang University (No. 2016126) and informed consent was taken from all the patients.

Open Access Statement: This is an Open Access article distributed in accordance with the Creative Commons Attribution-NonCommercial-NoDerivs 4.0 International License (CC BY-NC-ND 4.0), which permits the noncommercial replication and distribution of the article with the strict proviso that no changes or edits are made and the original work is properly cited (including links to both the formal publication through the relevant DOI and the license). See: https://creativecommons.org/licenses/by-nc-nd/4.0/. 


\section{References}

1. Tazuma S. Gallstone disease: Epidemiology, pathogenesis, and classification of biliary stones (common bile duct and intrahepatic). Best Pract Res Clin Gastroenterol 2006;20:1075-83.

2. Zhang W, Wang BY, Du XY, et al. Big-data analysis: A clinical pathway on endoscopic retrograde cholangiopancreatography for common bile duct stones. World J Gastroenterol 2019;25:1002-11.

3. Portincasa P, Di Ciaula A, de Bari O, et al. Management of gallstones and its related complications. Expert Rev Gastroenterol Hepatol 2016;10:93-112.

4. Williams EJ, Green J, Beckingham I, et al. Guidelines on the management of common bile duct stones (CBDS). Gut 2008;57:1004-21.

5. Boerma D, Schwartz MP. Gallstone disease. Management of common bile-duct stones and associated gallbladder stones: Surgical aspects. Best Pract Res Clin Gastroenterol 2006;20:1103-16.

6. Lacitignola S, Minardi M. Management of common bile duct stones: a ten-year experience at a tertiary care center. JSLS 2008; 12:62-5.

7. van Dijk AH, Lamberts M, van Laarhoven CJ, et al. Laparoscopy in cholecysto-choledocholithiasis. Best Pract Res Clin Gastroenterol 2014;28:195-209.

8. Lyass S, Phillips EH. Laparoscopic transcystic duct common bile duct exploration. Surg Endosc 2006;20 Suppl 2:S441-5.

9. Bansal VK, Misra MC, Garg P, et al. A prospective randomized trial comparing two-stage versus singlestage management of patients with gallstone disease and common bile duct stones. Surg Endosc 2010;24:1986-9.

10. Chan DS, Jain PA, Khalifa A, et al. Laparoscopic common bile duct exploration. Br J Surg 2014;101:1448-52.

11. Leida $Z$, Ping B, Shuguang $W$, et al. A randomized comparison of primary closure and T-tube drainage of the common bile duct after laparoscopic choledochotomy. Surg Endosc 2008;22:1595-600.

12. Wills VL, Gibson K, Karihaloot C, et al. Complications of biliary T-tubes after choledochotomy. ANZ J Surg 2002;72:177-80.

13. Rienhoff WF. Primary Closure of the Common Duct. Ann Surg 1960;151:255-60.

14. Wang P, Li ZS, Liu F, et al. Risk factors for ERCP-related complications: a prospective multicenter study. Am J Gastroenterol 2009;104:31-40.

15. Lei J, Wang J, Li Q, et al. Laparoscopic Transcystic
Common Bile Duct Exploration: T-Shaped Incision of Cystic Duct with FREDDY Laser Lithotripsy. J Laparoendosc Adv Surg Tech A 2016;26:646-51.

16. Fang L, Wang J, Dai WC, et al. Laparoscopic transcystic common bile duct exploration: surgical indications and procedure strategies. Surg Endosc 2018;32:4742-8.

17. Hongjun H, Yong J, Baoqiang W. Laparoscopic common bile duct exploration: choledochotomy versus transcystic approach? Surg Laparosc Endosc Percutan Tech 2015;25:218-22.

18. Fuente I, Beskow A, Wright F, et al. Laparoscopic transcystic common bile duct exploration as treatment for choledocholithiasis after Roux-en-Y gastric bypass. Surg Endosc 2021;35:6913-20.

19. Hanif F, Ahmed Z, Samie MA, et al. Laparoscopic transcystic bile duct exploration: the treatment of first choice for common bile duct stones. Surg Endosc 2010;24:1552-6.

20. Manes G, Paspatis G, Aabakken L, et al. Endoscopic management of common bile duct stones: European Society of Gastrointestinal Endoscopy (ESGE) guideline. Endoscopy 2019;51:472-91.

21. Hu Y, Kou DQ, Guo SB. The influence of periampullary diverticula on ERCP for treatment of common bile duct stones. Sci Rep 2020;10:11477.

22. Zhu J, Sun G, Hong L, et al. Laparoscopic common bile duct exploration in patients with previous upper abdominal surgery. Surg Endosc 2018;32:4893-9.

23. Yun KW, Ahn YJ, Lee HW, et al. Laparoscopic common bile duct exploration in patients with previous upper abdominal operations. Korean J Hepatobiliary Pancreat Surg 2012;16:154-9.

24. Vecchio R, MacFadyen BV. Laparoscopic common bile duct exploration. Langenbecks Arch Surg 2002;387:45-54.

25. Wu X, Yang Y, Dong P, et al. Primary closure versus T-tube drainage in laparoscopic common bile duct exploration: a meta-analysis of randomized clinical trials. Langenbecks Arch Surg 2012;397:909-16.

(English Language Editor: J. Gray)

Cite this article as: Fang L, Huang J, Zheng H, Duan ZQ, Liu TD, Xiong H, Li W, Fu XW, Gao JF, Le H, Hu W, Liang B, Zhu XG. Laparoscopic transcystic common bile duct exploration in patients with a nondilated common bile duct. Ann Palliat Med 2021;10(12):12845-12856. doi: 10.21037/apm-213609 